\title{
Clinical and neurological evaluation following treatment with ultrasound and diathermy in dogs suffering from posterior paresis
}

\author{
A. Tikoo ${ }^{1}$, N. Arora ${ }^{1}$, G. Kumar ${ }^{1}$, D. K. Tiwari ${ }^{1 *}$, S. Sharma ${ }^{2}$, \\ A. Kumar ${ }^{1}$ and D. Kaushik ${ }^{1}$
}

\begin{abstract}
${ }^{1}$ Department of Veterinary Surgery and Radiology, Lala Lajpat Rai University of Veterinary and Animal Sciences, Hisar- 125004, Haryana, India; ${ }^{2}$ Department of Veterinary Clinical Complex, College of Veterinary Sciences, Lala Lajpat Rai University of Veterinary and Animal Sciences, Hisar- 125004, Haryana, India
\end{abstract}

\begin{abstract}
The present study was conducted on twelve clinical cases of dogs irrespective of age, breed and sex suffering from posterior paresis. Male dogs were more affected $(n=7)$ than females $(n=5)$. Posterior paresis was observed highest in Mongrel $(n=4)$ followed by Pomeranian and Labrador Retriever $(n=3$ each) breeds, respectively. Minimum occurrence was shown by German Shepherd and American Bully ( $n=1$ each). Age-wise maximum hospital occurrence was observed in dogs of 1- 3 years $(n=6)$, while the minimum was found in less than 1 year and more than 3 years of age $(n=3$ each). Lateral and ventro-dorsal radiographs of the spine (lumbo-sacral area) were taken in all the animals to evaluate the involvement of vertebral bodies, but no orthopaedic abnormality detected responsible for posterior paresis. Numeric pain score was found to be reduced significantly after treatment in both the groups indicative of improvement in pain and hind limb weakness in dogs with posterior paresis. Further, shortwave diathermy was found to be more effective as compared to therapeutic ultrasound in the management of posterior paresis in dogs.
\end{abstract}

Key words: Dogs, Pain Score, Posterior paresis, Shortwave diathermy, Ultrasound therapy

\section{INTRODUCTION}

Posterior paresis is the most common manifestation of spinal cord diseases which involves loss of bilateral rear limb motor control due to neural or muscular system dysfunction, leading to weight-bearing problems, paresis or limb paralysis, along with urinary and faecal incontinence (McGowan et al., 2007). It may result as sequelae to the spinal cord injury either by fall, jump from a height, road traffic accident, dog bite over the vertebral column, malicious blow by a stick, crush by a heavy object, fracture and myoclonus form of canine distemper (Hoerlein, 1978). The degree of posterior paresis will depend upon the extent of the compression of the spinal cord or the degree of involvement of nerves. In mild degree of spinal cord compression or neuritis, the clinical manifestation will be pain and mild ataxia (Brisson, 2010). In moderate degree of spinal cord compression or neuritis, the clinical manifestation will be ischemia of spinal cord causing muscular weakness and ataxia (Lorenz et al., 2011) and in severe cases when there is compression of multiple spinal nerves, there will be loss of movement of tail and limbs. There will be no control over urination, defecation and absence of sensation over the entire hind portion due to which animal is not able to lift the hind portion and most of the time adopt only sitting posture (Scott, 1997). The treatment option will depend on the type of stage of posterior paresis. In mild degree of spinal nerve involvement, the treatment regimen can be rest, analgesic and antiinflammatory drugs (Mann et al., 2007). In moderate degree of spinal nerve involvement, the medical treatment combined with physiotherapy can give a good response (Rai, 1975) and in severe cases prognosis is usually considered grave. However, physiotherapy in conjunction with conventional treatment always results in early recovery (McGowan et al., 2007;

"Corresponding Author 


\section{Posterior paresis in dogs}

Zama et al., 2013). Conservative drug therapy includes the administration of NSAIDs, corticosteroids and nervine tonics. NSAIDs are commonly used for painful conditions and injuries in animals. Prostaglandins are implicated in the production of inflammatory pain and sensitizing nociceptors to the action of other mediators (Cashman and McAnuthy, 1995). Nervine tonics are necessary for normal fatty acid production which plays a major role in improving neuronal membrane synthesis and integrity (Read and Harrington, 1981). Therefore, the present study was undertaken to evaluate the clinical and neurological parameters following treatment with ultrasound and diathermy in dogs suffering from posterior paresis.

\section{MATERIALS AND METHODS}

The present study was conducted from January to December 2020 on twelve clinical cases of dogs irrespective of age, breed and sex referred to the department suffering from posterior paresis. Detailed history and gross examination were conducted on the day of presentation in all the animals for posture and gait. These animals were randomly divided into two groups comprising six animals in each group. Rectal temperature $\left({ }^{\circ} \mathrm{F}\right)$, heart rate (beats/ $\mathrm{min}$ ), pulse rate (beats/min) and respiratory rate (breaths/min) were recorded in all the animals on the day of presentation, $3^{\text {rd }}$ and $7^{\text {th }}$ day of treatment. Neurological examination without giving any sedation or anesthesia was carried out in a quiet place on the day of presentation, $3^{\text {rd }}$ and $7^{\text {th }}$ day, and parameters such as conscious proprioception, patellar reflex, panniculus/cutaneous trunci reflex, perineal/ anal reflex, superficial (cutaneous) nociception reflex, deep nociception reflex and urinary bladder incontinence were evaluated as per Bali (2000). On the day of presentation, lateral (L) and ventro-dorsal (VD) radiographs of the spine (lumbo-sacral area) were taken in all the animals for radiological interpretation.

\section{Ultrasound therapy}

In Group-I animals, ultrasound therapy was applied after clipping hairs over the thigh muscles of the affected side and applying ultrasound jelly to ensure perfect contact between the transducer head and skin. Sonication was performed at a frequency of $1 \mathrm{MHz}$, an intensity of $0.5 \mathrm{watt} / \mathrm{cm}^{2}$ (SATA), daily 10 minutes for 7 days in a pulsed mode $(1: 4)$ as per the standard technique suggested by Ansari et al. (2012). The transducer was moved slowly in a proximal-distal linear way on the skin surface (Fig. 1).

\section{Shortwave diathermy}

Shortwave diathermy was given in group II animals using two pads at the hind quarter region (lumbo-sacral or hip region) depending upon the site of lesion or trauma, each on either side of the vertebral column, $200 \mathrm{~mA}$ intensity and 10 volts alternating current depending upon the degree of trauma and the size of the patient (Fig. 2) as per the standard technique suggested by Ansari et al. (2012). Treatment was given daily for 10 minutes for 7 days.

\section{Supportive therapy}

In addition to physiotherapy techniques, animals of both groups were treated with supportive medicinal therapy including analgesic and anti-inflammatory drug, meloxicam@0.2 mg/kg body weight; nervine tonic containing methylcobalamin (Vit. $\mathrm{B}_{12}$ ) $500 \mathrm{mcg}$, nicotinamide (Vit. $\mathrm{B}_{3}$ ) $45 \mathrm{mg}$ and pyridoxine (Vit. $\mathrm{B}_{6}$ ) $1.5 \mathrm{mg}$ per $15 \mathrm{~mL} @ 5-10$ mL twice daily, cholecalciferol 60,000 I.U. @ 1 sachet per $20 \mathrm{~kg}$ body weight, per orally; daily for 5 days.

\section{Pain score assessment}

The pain assessment was made by adopting a multifactorial numerical rating scale (NRS). Seven behaviours included in the scale were posture, vocalization, appetite and thirst, personality or attitude, response to palpation, facial expression and mental status. All behavioral parameters except appetite and thirst were graded in a multifactorial score from 0 to $3(0=$ no pain, $1=$ mild pain, $2=$ moderate pain, $3=$ severe pain). Appetite and thirst were graded from $0-2(0=$ normal; $1=$ partial; $2=$ complete $)$ 
Indian Journal of Animal Health, June, 2021

Posterior paresis in dogs

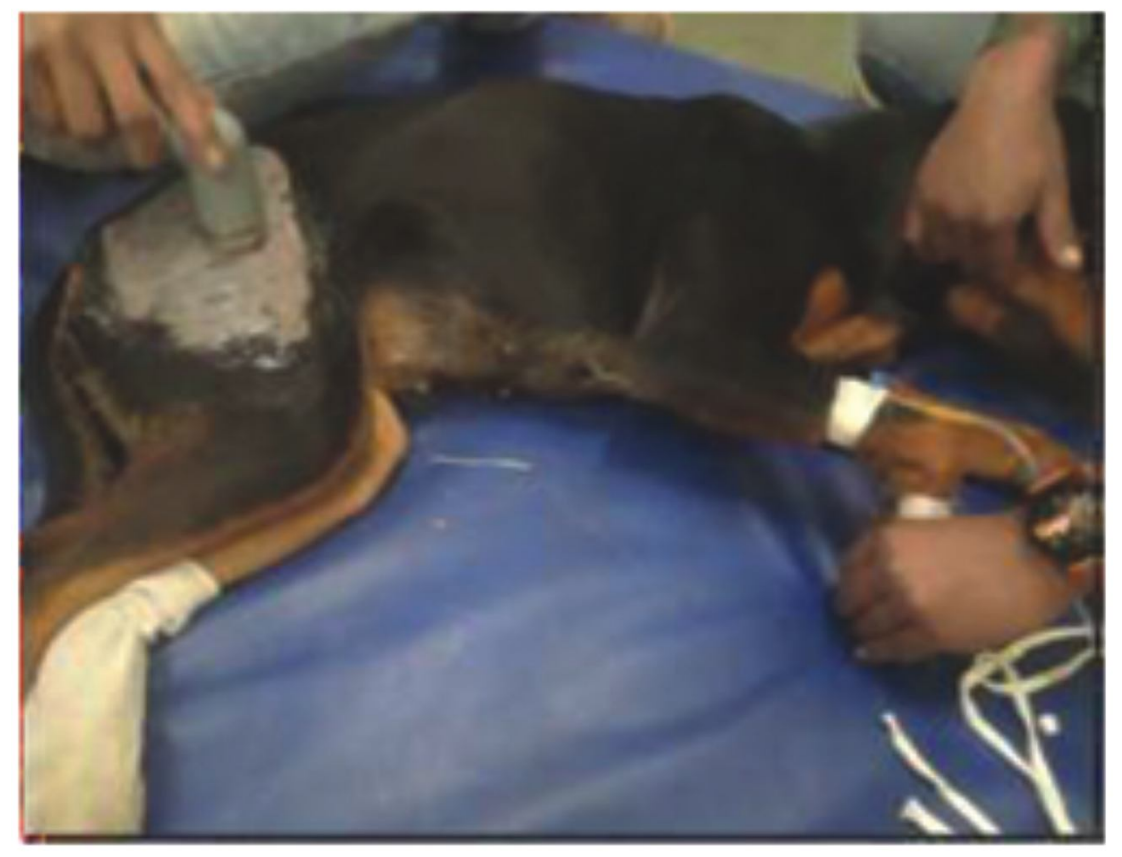

Fig. 1. Dog subjected to ultrasound therapy

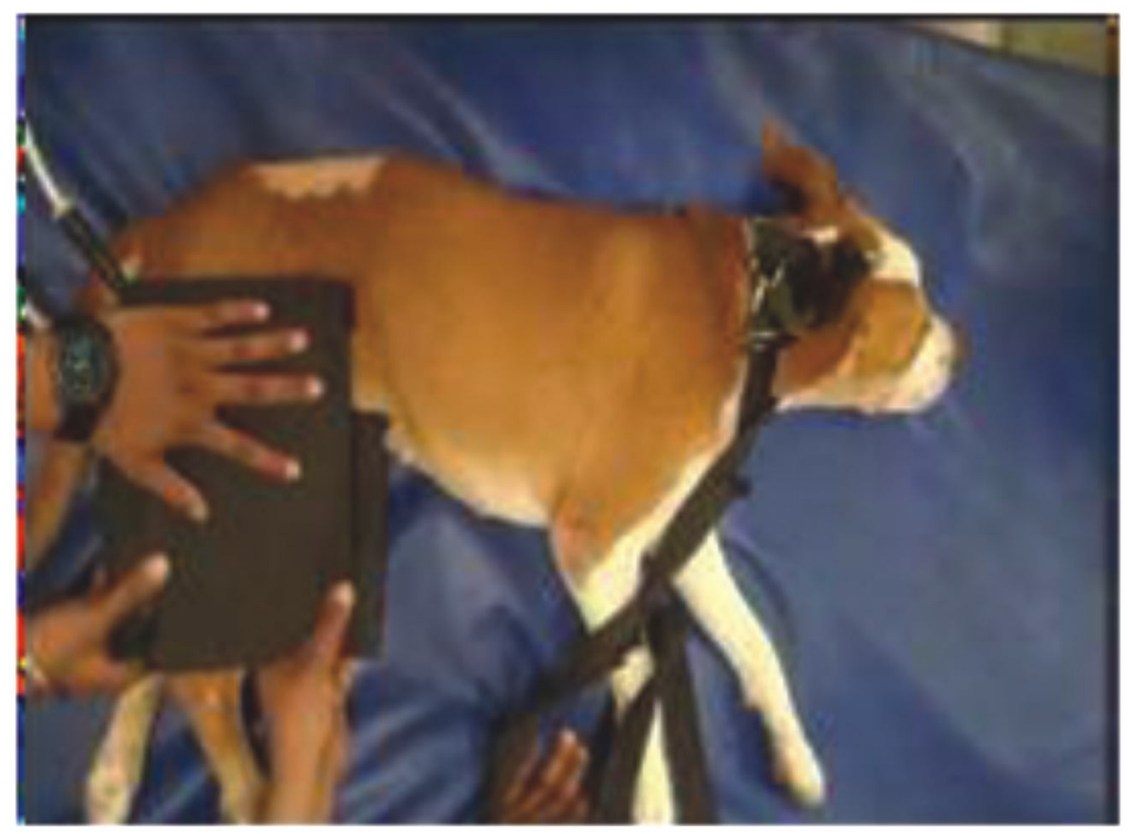

Fig. 2. Dog subjected to shortwave diathermy using heating pads 
only. The schedule protocol for pain scoring was $0,3^{\text {rd }}$ and $7^{\text {th }}$ day.

\section{Statistical analysis}

The data obtained were analyzed using two-way Analysis of Variance (ANOVA) followed by Duncan Multiple Range Test (DMRT) using SPSS 16.0 version. The level of statistical significance for all comparisons was established at $\mathrm{P}<0.05$. The values obtained were compared between and within the groups.

\section{RESULTS}

The age-wise maximum occurrence was observed in dogs of 1 to 3 years $(n=6,50 \%)$, while minimum was found in less than 1 year and more than 3 years of age $(n=3,25 \%$ each $)$ as shown in Fig. 3. Male dogs were more affected $(n=7,58.33 \%)$ than females $(n=5,41.67 \%)$. Sexwise distribution is shown in Fig. 4. The cases reported were highest in Mongrel $(n=4,33.33 \%)$ followed by Pomeranian and Labrador Retriever $(n=3,25 \%$ each) breeds of dog. Minimum breedwise occurrence was observed in German Shepherd and American Bully $(\mathrm{n}=1,8.33 \%$ each). Breed-wise distribution is shown in Fig. 5 . The majority of the cases $(n=5,41.66 \%)$ were brought to the department between 1-5 days of the initiation of illness followed by 15-30 days $(\mathrm{n}=3,25 \%)$ and $5-10$ days $(\mathrm{n}=2 ; 16.66 \%)$. Only 1 animal $(8.33 \%)$ each was brought between 10 15 days and 20-25 days of the commencement of illness (Fig. 6). There was no or unknown history of physical trauma in five cases $(41.66 \%)$, while in the rest of the cases, trauma was the known causative factor of the disease, which includes fall from a height in four (33.33\%), hitting by a hard object in one $(8.33 \%)$ and automobile accident in two (16.66\%) dogs, respectively. Etiology-wise distribution is shown in Fig. 7.

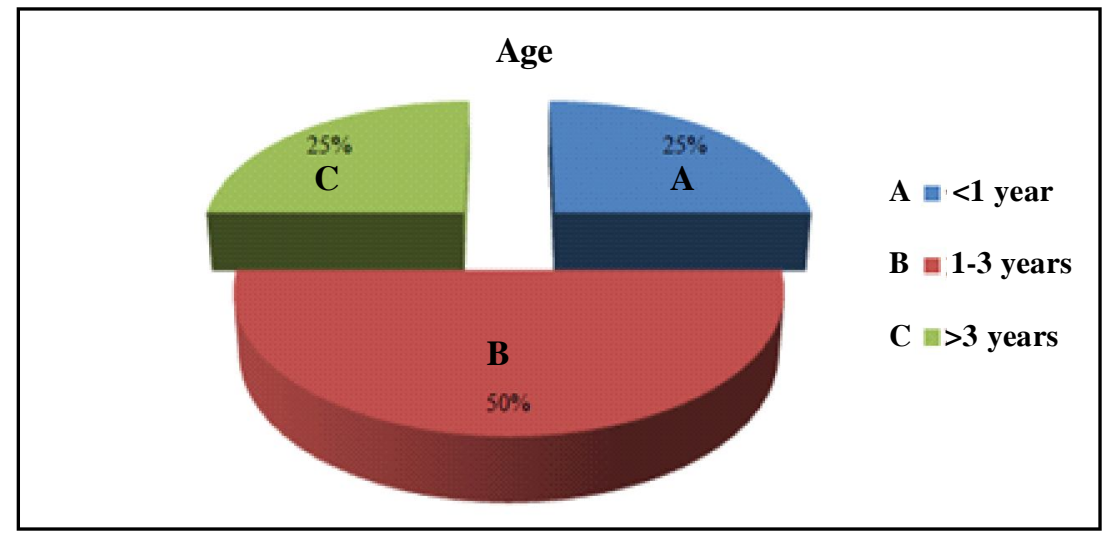

Fig. 3. Age-wise occurrence of posterior paresis in dogs

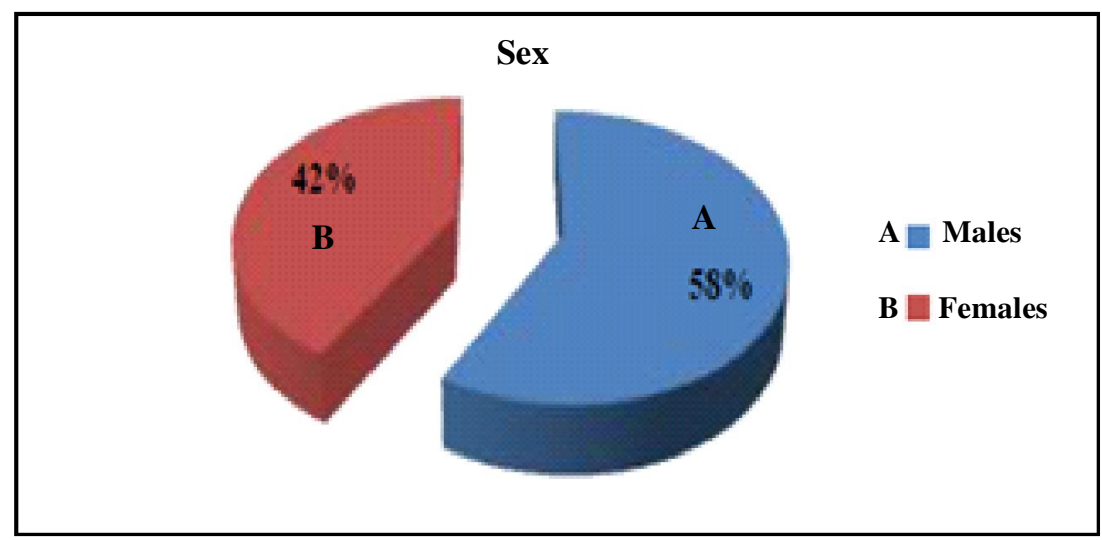

Fig. 4. Sex-wise occurrence of posterior paresis in dogs 


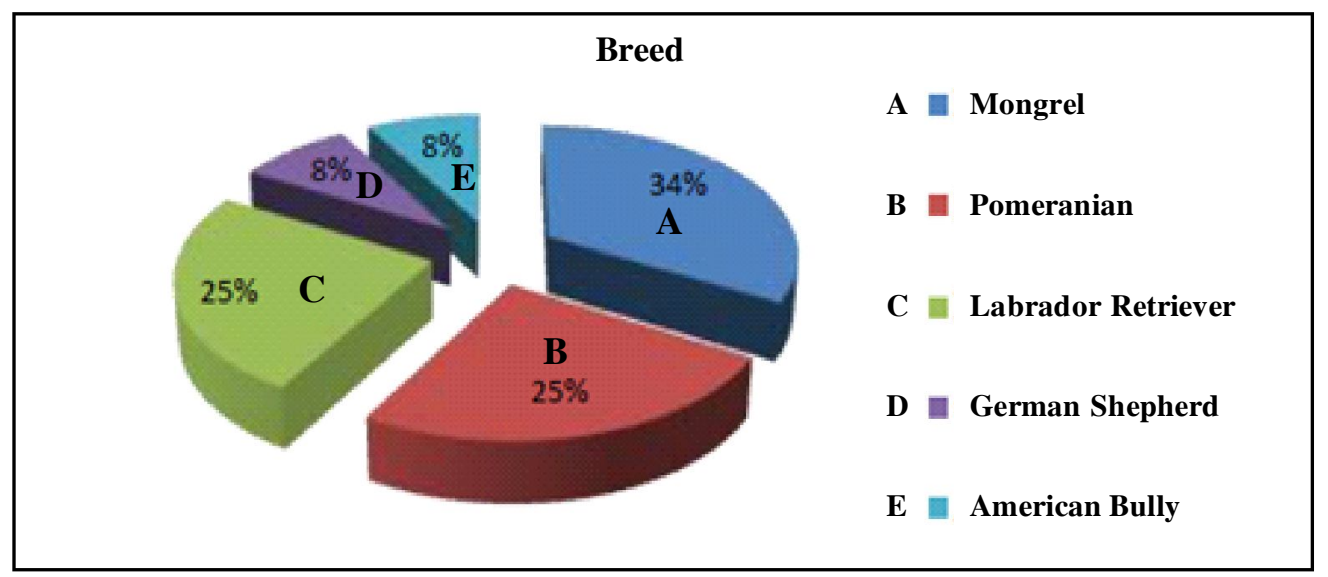

Fig. 5. Breed-wise occurrence of posterior paresis in dogs

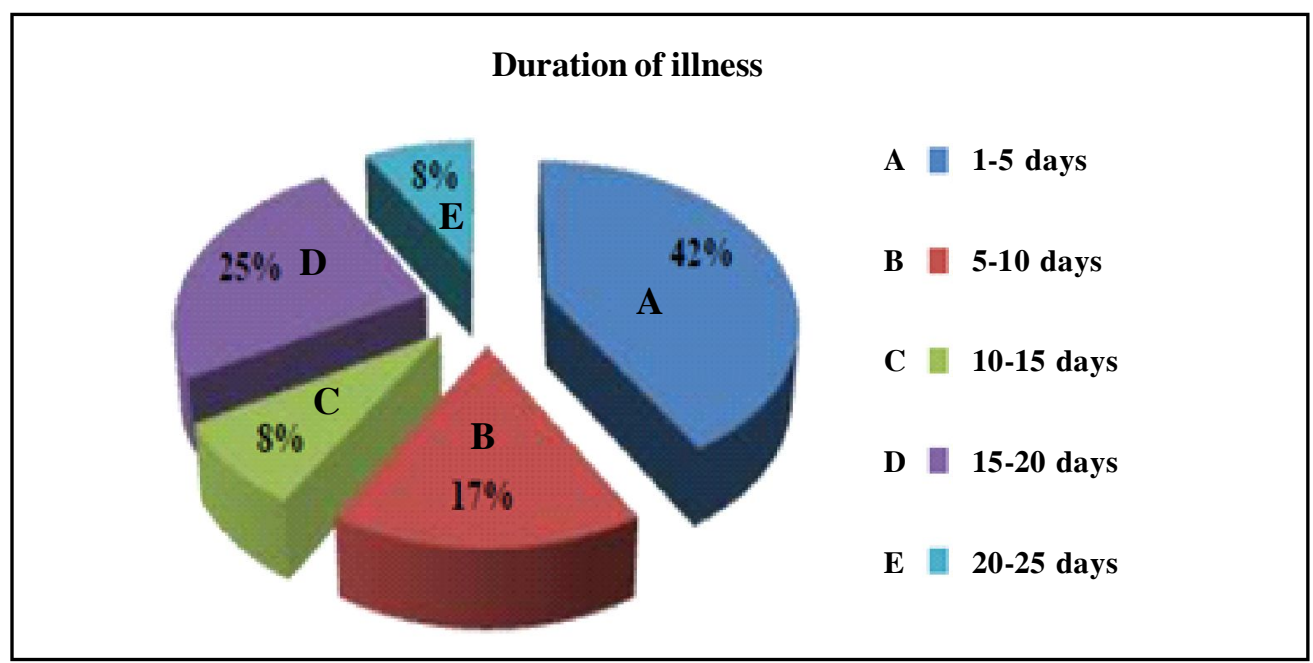

Fig. 6. Duration of illness-wise occurrence of posterior paresis in dogs

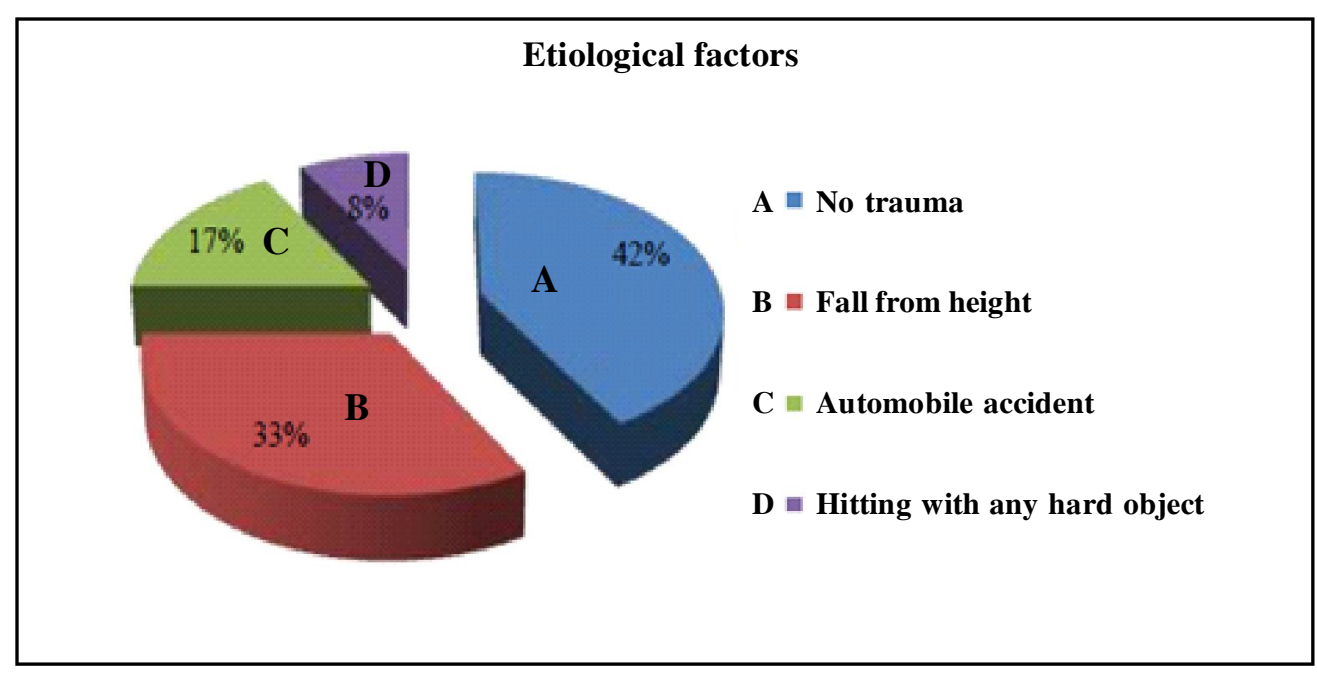

Fig. 7. Etiological factor-wise occurrence of posterior paresis in dogs 
Table 1. Effect of Ultrasound Therapy and Shortwave Diathermy on pain management at different time intervals $(M e a n \pm S E)$

\begin{tabular}{cccc}
\hline Pain score & Day 0 & Day 3 & Day 7 \\
\hline Group I & $6.17 \pm 0.95^{\mathrm{aB}}$ & $3.00 \pm 0.49^{\mathrm{aAB}}$ & $0.83 \pm 0.77^{\mathrm{aA}}$ \\
Group II & $5.33 \pm 0.60^{\mathrm{aC}}$ & $2.67 \pm 0.45^{\mathrm{aB}}$ & $2.00 \pm 0.31^{\mathrm{aA}}$ \\
\hline
\end{tabular}

Values without a common superscript letter A-C are significantly different within groups $(\mathrm{P}<0.05)$

Values without a common superscript letter a-c are significantly different between groups $(\mathrm{P}<0.05)$

Table 2. Effect of Ultrasound Therapy on neurological response in group I at different time intervals

\begin{tabular}{|c|c|c|c|c|c|c|c|}
\hline $\begin{array}{l}\text { Neurological } \\
\text { signs }\end{array}$ & $\begin{array}{c}\text { Conscious } \\
\text { proprioception }\end{array}$ & $\begin{array}{l}\text { Patellar } \\
\text { reflex }\end{array}$ & $\begin{array}{c}\text { Cutaneous } \\
\text { truncii }\end{array}$ & $\begin{array}{l}\text { Anal } \\
\text { reflex }\end{array}$ & $\begin{array}{l}\text { Superficial } \\
\text { nociception }\end{array}$ & $\begin{array}{c}\text { Deep } \\
\text { nociception }\end{array}$ & $\begin{array}{c}\text { Urinary } \\
\text { Reflex }\end{array}$ \\
\hline \multicolumn{8}{|c|}{ Case no. 1} \\
\hline$\overline{\text { Day } 0}$ & 0 & -1 & -1 & +1 & Absent & Present & Tonic \\
\hline Day 3 & 1 & -1 & -1 & +1 & Present & Present & Tonic \\
\hline Day 7 & 2 & 0 & 0 & +1 & Present & Present & Flaccid \\
\hline \multicolumn{8}{|c|}{ Case no. 2} \\
\hline$\overline{\text { Day } 0}$ & 1 & 0 & 0 & +1 & Present & Present & Flaccid \\
\hline Day 3 & 1 & 0 & +1 & +1 & Present & Present & Flaccid \\
\hline Day 7 & 2 & 0 & +1 & +1 & Present & Present & Flaccid \\
\hline \multicolumn{8}{|c|}{ Case no. 3} \\
\hline$\overline{\text { Day } 0}$ & 2 & -1 & 0 & -1 & Present & Present & Flaccid \\
\hline Day 3 & 2 & 0 & +1 & 0 & Present & Present & Flaccid \\
\hline Day 7 & 2 & 0 & +1 & +1 & Present & Present & Flaccid \\
\hline \multicolumn{8}{|c|}{ Case no. 4} \\
\hline$\overline{\text { Day } 0}$ & 0 & -1 & +1 & -1 & Present & Present & Flaccid \\
\hline Day 3 & 1 & 0 & +1 & 0 & Present & Present & Flaccid \\
\hline Day 7 & 1 & 0 & +1 & +1 & Present & Present & Flaccid \\
\hline \multicolumn{8}{|c|}{ Case no. 5} \\
\hline Day 0 & 1 & -1 & -1 & +1 & Present & Present & Flaccid \\
\hline Day 3 & 1 & -1 & 0 & +1 & Present & Present & Flaccid \\
\hline Day 7 & 2 & 0 & +1 & +1 & Present & Present & Flaccid \\
\hline \multicolumn{8}{|c|}{ Case no. 6} \\
\hline Day 0 & 0 & 0 & -1 & -1 & Present & Present & Flaccid \\
\hline Day 3 & 1 & 0 & 0 & -1 & Present & Present & Flaccid \\
\hline Day 7 & 2 & 0 & +1 & +1 & Present & Present & Flaccid \\
\hline
\end{tabular}

All the animals of the present study exhibited the symptoms of pain as manifested by wide base stance, arching of back or kyphosis, urinary incontinence, crepitation and decreased range of motion with flaccid paresis and dragging of hind limbs. Postural deficits like tucked up abdomen with head down posture and lateral recumbency was observed in nine $(75.00 \%)$ cases on the day of presentation. Vocalization was observed in six $(50.00 \%)$ cases, when dogs were forced to move which came to normal by $3^{\text {rd }}$ day of treatment except in one case. Inappetence along with anorexia was observed in three $(25.00 \%)$ 
dogs while eight $(66.67 \%)$ dogs were reluctant to take solid food. Normal food intake resumed in all animals by the $7^{\text {th }}$ day of treatment except in two cases. Mild to strong pain response was elicited on touching the affected area in four $(34.00 \%)$ cases. No response to touch was shown by all the animals after day $7^{\text {th }}$ posttreatment. Licking and scratching of the affected

Table 3. Effect of Shortwave Diathermy on neurological response in group II at different time intervals

\begin{tabular}{|c|c|c|c|c|c|c|c|}
\hline $\begin{array}{l}\text { Neurological } \\
\text { signs }\end{array}$ & $\begin{array}{c}\text { Conscious } \\
\text { proprioception }\end{array}$ & $\begin{array}{l}\text { Patellar } \\
\text { reflex }\end{array}$ & $\begin{array}{c}\text { Cutaneous } \\
\text { truncii }\end{array}$ & $\begin{array}{l}\text { Anal } \\
\text { reflex }\end{array}$ & $\begin{array}{l}\text { Superficial } \\
\text { nociception }\end{array}$ & $\begin{array}{c}\text { Deep } \\
\text { nociception }\end{array}$ & $\begin{array}{c}\text { Urinary } \\
\text { Reflex }\end{array}$ \\
\hline \multicolumn{8}{|c|}{ Case no. 1} \\
\hline$\overline{\text { Day } 0}$ & 1 & -2 & +1 & -1 & Absent & Present & Flaccid \\
\hline Day 3 & 1 & -1 & +1 & 0 & Present & Present & Flaccid \\
\hline Day 7 & 2 & -1 & +1 & +1 & Present & Present & Flaccid \\
\hline \multicolumn{8}{|c|}{ Case no. 2} \\
\hline$\overline{\text { Day } 0}$ & 1 & -1 & -1 & +1 & Present & Present & Tonic \\
\hline Day 3 & 1 & -1 & +1 & +1 & Present & Present & Tonic \\
\hline Day 7 & 2 & 0 & +1 & +1 & Present & Present & Flaccid \\
\hline \multicolumn{8}{|c|}{ Case no. 3} \\
\hline$\overline{\text { Day } 0}$ & 1 & -2 & -1 & -1 & Absent & Present & Tonic \\
\hline Day 3 & 2 & -1 & -1 & 0 & Present & Present & Tonic \\
\hline Day 7 & 2 & 0 & 0 & +1 & Present & Present & Flaccid \\
\hline \multicolumn{8}{|c|}{ Case no. 4} \\
\hline$\overline{\text { Day } 0}$ & 0 & -1 & -1 & +1 & Present & Present & Flaccid \\
\hline Day 3 & 1 & 0 & 0 & +1 & Present & Present & Flaccid \\
\hline Day 7 & 1 & 0 & +1 & +1 & Present & Present & Flaccid \\
\hline \multicolumn{8}{|c|}{ Case no. 5} \\
\hline$\overline{\text { Day } 0}$ & 0 & -1 & +1 & -1 & Present & Present & Flaccid \\
\hline Day 3 & 1 & 0 & +1 & 0 & Present & Present & Flaccid \\
\hline Day 7 & 2 & 0 & +1 & +1 & Present & Present & Flaccid \\
\hline \multicolumn{8}{|c|}{ Case no. 6} \\
\hline$\overline{\text { Day } 0}$ & 0 & 0 & +1 & -1 & Present & Present & Flaccid \\
\hline Day 3 & 1 & 0 & +1 & 0 & Present & Present & Flaccid \\
\hline Day 7 & 2 & 0 & +1 & +1 & Present & Present & Flaccid \\
\hline
\end{tabular}

Table 4. Effect of Ultrasound Therapy and Shortwave Diathermy on physiological parameters at different time intervals $($ Mean \pm SE)

\begin{tabular}{lcccccc}
\hline Parameters & \multicolumn{3}{c}{ Group I } & \multicolumn{3}{c}{ Group II } \\
& Day 0 & Day 3 & Day 7 & Day 0 & Day 3 & Day 7 \\
\hline RT ( ${ }^{\circ}$ F) & $101.83 \pm 0.21^{\mathrm{aA}}$ & $102.74 \pm 0.32^{\mathrm{aA}}$ & $102.93 \pm 0.01^{\mathrm{aA}}$ & $101.33 \pm 0.32^{\mathrm{aA}}$ & $102.72 \pm 0.11^{\mathrm{aA}}$ & $102.98 \pm 0.45^{\mathrm{aA}}$ \\
HR (/min.) & $99.17 \pm 0.12^{\mathrm{aA}}$ & $103.17 \pm 0.03^{\mathrm{aB}}$ & $104.00 \pm 0.44^{\mathrm{aB}}$ & $98.83 \pm 0.87^{\mathrm{aA}}$ & $102.83 \pm 0.43^{\mathrm{aB}}$ & $103.67 \pm 0.23^{\mathrm{aB}}$ \\
PR (/min.) & $97.22 \pm 0.02^{\mathrm{aA}}$ & $101.17 \pm 0.24^{\mathrm{aB}}$ & $103.35 \pm 0.42^{\mathrm{aB}}$ & $98.23 \pm 0.47^{\mathrm{aA}}$ & $102.22 \pm 0.33^{\mathrm{aB}}$ & $104.17 \pm 0.34^{\mathrm{aB}}$ \\
RR (/min.) & $29.00 \pm 0.98^{\mathrm{aA}}$ & $28.90 \pm 1.32^{\mathrm{aA}}$ & $29.33 \pm 1.33^{\mathrm{aA}}$ & $29.67 \pm 0.77^{\mathrm{aA}}$ & $29.68 \pm 0.43^{\mathrm{aA}}$ & $30.17 \pm 2.01^{\mathrm{aA}}$ \\
\hline
\end{tabular}

Values without a common superscript letter A-C are significantly different within groups $(\mathrm{P}<0.05)$

Values without a common superscript letter a-c are significantly different between groups $(\mathrm{P}<0.05)$ 
painful area was observed in four $(33.33 \%)$ cases, while eight (66.67\%) dogs became docile and quiet in attitude. Most of them showed recovery within one week except four dogs which were still in pain.

The mean \pm SE values of numeric pain score (NRS) at various time intervals have been shown in Table 1. Pain score values showed a significant $(\mathrm{P}<0.05)$ decrease between day 0 and 7 in group I and II.

The detailed neurological examination was recorded without giving any sedation or anesthesia on day $0,3^{\text {rd }}$ and $7^{\text {th }}$ day of the treatment. Patellar, pelvic withdrawal, panniculus, anal and conscious proprioception reflexes were recorded as per Bali (2000). All the examinations were done in a quiet place and the observations have been depicted in Table 2 and 3. The proprioception deficit was observed in six ( $n=3$ in each group) dogs. The response after 3 seconds was recorded in five $\operatorname{dogs}(n=2$ in group I and $n=3$ in group II) whereas the response within 3 seconds was observed in one dog of group I out of 12 dogs. Proprioceptive reflex showed normal response till day 7 in ten ( $n=5$ in each group) dogs. Three $\operatorname{dogs}(n=2$ in group I and $n=1$ in group II) out of $12 \mathrm{dogs}$ affected with posterior paresis had normal patellar reflex, whereas seven $(n=4$ in group I and $n=3$ in group II) showed diminished reflex and two (in group II) showed no reflex. Patellar reflex returned to normal in five $\operatorname{dogs}(n=3$ in group I and $n=2$ in group II) on day 3 and four dogs ( $n=2$ in each group) on day 7 of treatment. Deep pain perception was present in all the dogs. However, superficial pain perception was absent in three $(\mathrm{n}=1$ in group I and $n=2$ in group II) dogs and present in the rest. The pain sensations were back to normal till day 3 in all three dogs. Cutaneous truncii/ Panniculus reflex was normal in four dogs $(n=$ 1 in group I and $n=3$ in group II), diminished in six $\operatorname{dog} s(n=3$ in each group) and slightly decreased in two $\operatorname{dogs}(n=2$ in group I). Panniculus reflex returned to normal in three $\operatorname{dogs}(n=2$ in group I and $n=1$ in group II) on the $3^{\text {rd }}$ day and in five $\operatorname{dogs}(\mathrm{n}=2$ in group I and $\mathrm{n}=1$ in group II) on day 7 . Anal reflex was normal in five $\operatorname{dogs}(n=3$ in group $I$ and $n=2$ group II). Seven $\operatorname{dogs}(n=3$ in group I and $n=4$ in group II) exhibited diminished reflex which returned to normal in all the dogs till day 7 .

The mean \pm SE values of rectal temperature $\left({ }^{\circ} \mathrm{F}\right)$, heart rate (beats/min.), pulse rate (pulse/min.) and respiration rate (breaths/ min.) at different time intervals have been shown in table 4 . The rectal temperature $\left({ }^{\circ} \mathrm{F}\right)$ increased non-significantly $(\mathrm{P}<0.05)$ in both groups. The heart rate (beats/min.) and pulse rate (pulse/ min.) showed a significant $(\mathrm{P}<0.05)$ increase from day 0 to 3 in both the groups and a nonsignificant increase from day 3 to 7 . The respiration rate (breaths/min.) showed a nonsignificant $(\mathrm{P}<0.05)$ decrease from day 0 to 3 and non-significant increase from day 3 to 7 in group I, while group II showed non-significant increase from day 0 to day 7 .

Plain radiographic examinations in lateral and ventro-dorsal views of lumbo- sacral spine and the hip region were conducted in all the animals of group I and II on the day of presentation. However, no radiographic abnormalities were detected in the radiographs.

\section{DISCUSSION}

In the present study, younger age group animals have shown more occurrence than adult animals. High occurrence of posterior paresis in dogs between 1 to 5 years of age has also been observed by Sharma (2005), Gopinathan (2006) and Sharma et al. (2013) and is attributed to high activity and tendency to fight, jump and run during this age, which aggravate the damage to the spinal cord and surrounding structures. Posterior paresis is generally thought to be associated with old age but lesser health care and early death of old sick dogs may be the reason for low occurrence in older dogs as found in the present study.

The neurological deficits in this study are majorly affecting the male dogs which is in correlation with Sharma (2005) and Gopinathan (2006) as compared to female which might be attributed to the fact that male dogs as pets are 


\section{Posterior paresis in dogs}

mostly preferred by owners (Dämmrich, 1991) and they are more susceptible to trauma due to their high metabolic activity and aggressive and wandering behavior as compared to the female counterparts (Kolata, 1993).

The majority of animals reported in the present study are non-descript this might be due to the fact that Mongrels (non-descript breed) contribute to a major population of stray dogs. Only expensive exotic breeds are kept by people in order to show social status and comparatively pleasing looks.

Period of illness was observed highest in five animals $(41.66 \%)$ of 1-5 days followed by three animals (25\%) in 15-20 days, two animals $(16.66 \%)$ in $5-10$ days while rest one animal $(8.33 \%)$ each having duration of illness between 10-15 and 20-25 days, respectively. Gopinathan (2006) also recorded that majority of the dogs suffering from hind quarter weakness were reported within a week of the illness. Sharma (2005) recorded it to be between 10 to 30 days. Brown (1977), Butterworth and Denny (1991) have reported that the dogs with neurological deficit causing pain and inability to bear weight and visible urinary incontinence are attended early by the owners as compared to those showing simple back pain alone or with other less severe deficits.

The results of the present study were in accordance with the study by Gopinathan (2006) who also noticed maximum cases of posterior paresis with no or unknown history of trauma following falling from a height, automobile accident and hitting with a hard object respectively. Many developmental disorders like generalized osteoporosis, hypovitaminosis "D" and hypocalcaemia exhibited clinical signs of posterior paresis in the study conducted by Ettinger and Feldman (2010).

The neurological examination provided very useful information regarding the severity and exact location of the injury. However, there was individual variation in the sensitivity among the animals showing similar clinical symptoms. Patellar, pelvic withdrawal, panniculus, anal and conscious proprioception reflexes were recorded as per Bali (2000). Acute pain associated with sudden onset of injury provokes abnormal physiological and psychological reactions which may precipitate into complications like increased stress response, prolonged recovery, increased morbidity, prolongation of disability and at time death (Kehlet, 1988). Lesions involving spinal cord segments or lumbosacral nerve roots that include femoral, obturator, sciatic, pudendal, pelvic, and coccygeal nerves result in posterior paresis. In the present study, various neurological tests showed a marked improvement in GroupII followed by Group-I after complete treatment. Proprioceptive reflex showed normal response till day 7 in ten ( $n=5$ in each group) dogs. Similar finding was seen by Ansari (2012) where the majority of the cases took 7 days to show normal reflexes. Zama et al. (2013) also reported that animals regained normal postural reflexes and recovered early subjected to short wave diathermy followed by therapeutic ultrasound when used in conjunction with conventional treatment. However, Grewal (2016) mentioned that proprioception deficit returned to normal after 21 days of treatment in severe cases of posterior paresis.

Spinal cord injury resulted in depressed or absent patellar and withdrawal reflexes in pelvic limbs. Grewal (2016) also mentioned that patellar reflex got diminished in spinal cord injury which improved after continuous treatment. The present study showed an abnormal patellar reflex in cases of posterior paresis. The reflexes returned to normal in five dogs on day 3 and four dogs on day 7 of treatment.

The cutaneous trunci reflex allows localization of thoracolumbar spinal cord lesions. All the spinal cord lesions starting from L5 and continued cranially up to T2, showed a decrease in panniculus/ cutaneous trunci reflex. Panniculus reflex returned to normal in three $\operatorname{dogs}(n=2$ in group I and $n=1$ in group II) on the $3^{\text {rd }}$ day and in five $\operatorname{dogs}(n=2$ in group $I$ and $n=1$ in group II) on day 7. An absent or depressed anal reflex was usually observed in lesions of the sacral spinal cord segment (S1 to S3) or lesions affecting the pudendal nerve. It leads to flaccid or dilated anal sphincter resulting in faecal incontinence. Since the 
external anal sphincter is innervated by the pudendal nerve, which also originates in the sacral segments, the perineal (anal) reflex provides a good assessment of sacral spinal cord function. Similar findings were seen in dogs with a spinal injury where diminished anal reflexes returned to normal within 7 days in all the dogs. Urinary incontinence was observed in three animals on the day of presentation leading to tonic urinary bladder and dribbling of urine. The pudendal nerve innervates the urethral skeletal muscle. Lesions of the sacral segments will also result in loss of innervation to the skeletal muscle of the urethra. Lesions involving the pelvic nerves, sacral cord segments, or pathways to and from the brainstem will abolish the micturition reflex. As a result of minimal urethral resistance, manual expression of the bladder is easy in such cases. Thus, animals with sacral cord lesions may suffer from continual overflow incontinence. The micturition reflex returned to normal on the $3^{\text {rd }}$ day of treatment in all the affected animals. The observations were in accordance with the study by Grewal (2016) where he mentioned that if a lesion is at the lumbo-sacral level of the spine then the animal shows a decrease in voluntary micturition and easily expressible bladder.

In the present study, non-significant increase in rectal temperature following physiotherapy might be due to increased blood circulation and release of endorphin as also observed by Bromiley (1991). The tiny mineral ions in the blood become attracted to the magnetic field creating electrical currents in the blood stream. This, in turn, creates an increase in blood flow and heat in the area (Steyn et al., 2002).

A significant increase in heart rate and pulse rate from day 0 to $3^{\text {rd }}$ in both the groups was recorded following therapy. It was believed that the electrical stimulation increased blood flow over the site of treatment and muscle contraction (Hurley et al., 2001; Johnson and Tabassam, 2003). The increase in heart rate and pulse rate were in concurrence with the finding of Maiti et al. (2007) on ultrasound and interferential therapy in dogs.

The non-significant rise in the rate of respiration in dogs following therapy was in agreement with findings of Sharma et al., (2017) which that an increase in the blood supply and muscle contractions has enhanced the function of the hypothalamus respiratory center, which could be responsible for an increase in the rate of respiration after treatment.

The primary means of confirming a diagnosis and initial assessment with reference to neuromuscular disease remains conventional diagnostic radiography as suggested by Luttgen et al., (1988) and McKee (1992). However, in the present study initial assessment was made based on various neurological tests along with other signs shown by the animals and then a plain radiographic examination was conducted. All the cases revealed a normal ventro-dorsal and lateral radiograph with no lesion in the vertebral column or any part of the limb which signaled the condition to be of musculo-skeletal origin. The findings were in agreement with the studies of Gopinathan (2006) and Ansari (2012) in dogs suffering from posterior paresis.

It is concluded that numeric pain score was found to be reduced significantly after treatment in both the groups indicative of improvement in pain and hind limb weakness in dogs with posterior paresis. Improvement in neurological response and early ambulation was observed in Group-II animals as compared to Group-I. Thus, shortwave diathermy was found to be more effective as compared to therapeutic ultrasound in the management of posterior paresis in dogs.

Conflict of interest: Authors have no conflict of interest in this study.

\section{ACKNOWLEDGEMENT}

The authors are highly thankful to the Professor and Head of the department for providing the necessary facilities. Part of the study was funded through research grants from the Department of Veterinary Surgery and Radiology, College of Veterinary Sciences, Lala Lajpat Rai University of Veterinary and Animal Sciences, Hisar, Haryana. 


\section{REFERENCES}

Ansari MM, 2012. Evaluation of physiotherapeutic modalities for rehabilitation of dogs with hind quarter weakness. Part of $\mathrm{PhD}$ thesis submitted to Indian Veterinary Research Institute (Deemed University), Izatnagar- 243 122, Uttar Pradesh, India

Ansari MM, Zama MMS, Hoque M, Pawde AM and Dey S, 2012. Hind quarter weakness and its clinical management with haematobiochemical correlation - A Study of 24 canine patients. Intas Polivet, 13(2): 324-328

Bali RKC, 2000. Small Animal Neurology, Practical Seminar-2000. Department of Veterinary Surgery Radiology, PAU, Ludhiana, pp 1-8

Brisson BA, 2010. Intervertebral disc disease in dogs. Vet Clin Small Anim, 40(5): 829-858, doi: 10.1016/j.cvsm.2010.06.001

Bromiley MW, 1991. Therapeutic ultrasound. In: Physiotherapy in Veterinary Practice Oxford, England: Blackwell Scientific Publications Oxford, pp 76-84

Brown NO, 1977. Thoracolumbar disk disease in the dog. A retrospective analysis of 187 cases. J Am Anim Hosp Assoc, 13(6): 665-672

Butterworth SJ and Denny HR, 1991. Follow up study of 100 cases with thoracolumbar disc protrusions treated by lateral fenestration. J Small Anim Prac, 32(9): 443-447, doi: 10.1111/j.1748-5827.1991. tb00983.x

Cashman J and McAnuthy G, 1995. Nonsteroidal antiinflammatory drugs in perisurgical pain management. Drugs, 49(1): 51-70, doi: 10.2165/ 00003495-199549010-00005

Dämmrich K, 1991. Relationship between nutrition and bone growth in large and giant dogs. J Nutr, 121(11S): 114-121, doi:10.1093/jn/121.suppl_ 11.S114

Ettinger SJ and Feldman EC, 2010. Textbook of Veterinary Internal Medicine, $5^{\text {th }}$ edn., WB Saunders Company, Philadelphia, pp 212-234, 299, 306, 675-676, 1298-1325

Gopinathan A, 2006. Spinal disorder: diagnosis and their management in dogs and therapeutic evaluation of drugs and electroacupuncture in rabbits. $\mathrm{PhD}$ thesis, submitted to Indian Veterinary Research Institute (Deemed University), Izatnagar- 243 122, Uttar Pradesh, India

Grewal R, 2016. Neurological and therapeutic studies on posterior paresis in dogs. MVSc thesis submitted to Lala Lajpat Rai University of Veterinary and Animal Sciences, Hisar-125004, Haryana, India
Hoerlein BF, 1978. Canine Neurology, Diagnosis and Treatment. $2^{\text {nd }}$ edn., W.B. Saunders, Philadelphia, pp 53-70, 303-339

Hurley DA, Minder PM, McDonough SM, Walsh DM, Moore AP et al., 2001. Interferential therapy electrode placement technique in acute low back pain: A preliminary investigation. Arch Phys Med Rehabil, 82(4), 485-493, doi: 10.1053/ apmr.2001.21934

Johnson MI and Tabasam G, 2003. An investigation into the analgesic effects of different frequencies of the amplitude-modulated wave of interferential current therapy on cold-induced pain in normal subjects. Arch Phys Med Rehabil, 84(9): 13871394, doi: 10.1016/s0003-9993(03)00151-5

Kehlet H, 1988. Neural blockade in clinical anaesthesia. $2^{\text {nd }}$ edn., JB Lippincott, Philadelphia, pp145-188

Kolata RJ, 1993. Mechanisms and effects of trauma. In: Disease Mechanisms in Small Animal Surgery. Bojrab, MJ (Ed), $2^{\text {nd }}$ edn., Lea and Febiger, London, pp 7-9

Lorenz MD, Coates JR and Kent M, 2011. Handbook of Veterinary Neurology $5^{\text {th }}$ edn., St. Louis, Saunders/ Elsevier, pp 75-77

Luttgen PJ, Pechman RD and Hartsfiled SM, 1988. Neuroradiology. Vet Clin Small Anim Pract, 18(3): 501-528, doi: 10.1016/s0195$5616(88) 50052-9$

Maiti SK, Sharma A, Kumar N, Gupta OP and Sharma AK, 2007. Effect of ultrasound and interferential therapies on hindquarter weakness in dogs. Indian J Anim Sci, 77(12): 1273-1276

Mann FA, Wagner Mann CC, Dunphy ED, Ruben DS, Rochat MC et al., 2007. Recurrence rate of presumed thoracolumbar intervertebral disc disease in ambulatory dogs with spinal hyperpathia treated with anti inflammatory drugs: 78 cases (19972000). J Vet Emerg Crit Care, 17(1): 53- 60, doi: 10.1111/j.1476-4431.2006. 00195.x

McGowan C, Goff L and Stubbs N, 2007. Animal Physiotherapy: Assessment, Treatment and Rehabilitation of animals. Wiley-Blackwell, pp 102-124

McKee WM, 1992. A comparison of hemilaminectomy (with concomitant disc fenestration) and dorsal laminectomy for the treatment of thoracolumbar disc protrusion in dogs. Vet Record, 130(14): 296300, doi: 10.1136/vr.130.14.296

Rai R, 1975. Surgical Repair of the Femoral Fracture in Dogs with Special Reference to Radiographic and Angiographic Studies. PhD thesis submitted to 
Chaudhary Charan Singh Haryana Agricultural University, Hisar - 125 004, Haryana, India

Read DH and Harrington DD, 1981. Experimentally induced thiamine deficiency in Beagle dogs: clinical observations. Am J Vet Res, 42(6): 984991

Scott HW, 1997. Hemilaminectomy for the treatment of thoracolumbar disc disease in the dog: A followup study of 40 cases. J Small Anim Pract, 38(11): 488-494, doi: 10.1111/j.1748-5827.1997. tb03303.x

Sharma AK, 2005. Electroacupuncture and Physiotherapy in the Management of Hindquarter Weakness in Dogs. PhD thesis submitted to Indian Veterinary Research Institute (Deemed University), Izatnagar- 243 122, Uttar Pradesh, India

Sharma AK, Gupta OP, Singh GR, Pawde AM and Maiti
SK, 2013. Occurrence, clinical and radiographic study of hindquarter weakness in dogs. Indian J Anim Res, 47(3): 259-261

Sharma AK, Maiti SK and Pawde AM, 2017. Clinical and haemato-biochemical alterations following treatment with interferential therapy in the back pain in dogs. Explo AnimMed Res, 7(1): 64-68

Steyn PF, Ramey DW, Kirschvink J and Uhrig J, 2002. Effect of a static magnetic field on blood flow to the metacarpus in horses. J Am Vet Med Assoc, 217(6): 874-877, doi: 10.2460/javma.2000.217. 874

Zama MMS, Ansari MM, Dimri U, Hoque M, Maiti SK et al., 2013. Effect of therapeutic ultrasound and diathermy on oxidant-antioxidant balance in dogs suffering from hind quarter weakness. J Appl Anim Res, 41(1): 82-86, doi: 10.1080/ 09712119.2012 .738217

Received - 29.03.2021, Accepted - 11.05.2021, Published - 01.06.2021

Section Editor: Prof. S. K. Nandi, Associate Editor 